\title{
ETIMOLOGIA POPULAR
}

\author{
Artur de Almeida Tôrres \\ Niterói
}

"Forma a língua do povo fonte perene de mecanismos psicológicos" (Leite de Vasconcelos, Opúsc., I, 344)

A expressão etimologia popular, que aparece pela primeira vez em 1852, numa célebre revista berlinense, (1) foi empregada pelo alemão Förstemann, para designar o processo popular e inconsciente de formação homonímica ou paronímica de palavras ou sintagmas.

Esse curioso fenômeno, que é comum a tôdas as línguas, (2) ocorre quando a gente inculta ou semiculta, ao ouvir uma palavra ou expressão desconhecida, instintivamente a relaciona com outra que the é familiar, resultando dessa operação um novo produto que às vêzes se generaliza, chegando, não raro, a invadir a esfera das pessoas letradas.

Não devemos confundir êsse processo de adaptação do desconhecido ao conhecido com os casos típicos de analogia, embora se reconheça aí, até certo ponto, uma participação analógica. (3)

FERDINAND DE SAUSSURE procurou estabelecer judiciosa distinção entre êsses dois fenômenos da linguagem, acentuando que a analogia é um fato geral, pertencente ao funcionamento nor-

(1) Zeitschrift für vergleichende sprachforschung, herausgegeben von $D r$. Theodor Aufrecht und Dr. Adalbert Kuhn. Berlin.

(2) ADOLFO COELHO apresenta grande cópia de exemplos colhidos no grego, no latim, no valáquio, no português e no espanhol. (Cf. Quest. da líng. port., l, p. 109. Pôrto, 1874).

(3) MILLARDET enfende que não há antinomia absoluta entre etimol. pop. e analogia: " $\mathrm{Ce}$ sont deux phénomènes comparables en ce sens que, sur une forme $A$, agit une forme $B$, par suite d'une association d'idées plus ou moins complexe, d'où naît une forme C". (Linguistique et Dialectologie Romanes, p. 396). 
mal da língua, e que supõe sempre o esquecimento da forma anterior, nada tirando da substância dos elementos que ela substitui; ao passo que a etimologia popular só age em condições particulares, só atinge as formas desconhecidas, estrangeiras ou técnicas, reduzindo-se a uma interpretaçāo da forma antiga, sendo a lembrança desta, ainda que confusa, o ponto de partida da deformação que sofre.

E conclui:

"Ces deux phénomènes si ressemblants par certains côtés, s'opposent dans leur essence; ils doivent être soigneusement distingués". (Cours de Linguistique Générale, p. 240. Paris, 1931).

Alguns filólogos, levando em conta que o povo nāo faz etimologia conscientemente, e que as palavras ou frases forjadas por êsse meio não passam de associaçōes homonimicas irrefletidas, propõem se substitua a expressão etimologia popular por atração homonímica. (1) Embora razcável a proposta, julgamo-la um tanto intempestiva, de vez que a denominação antiga já está bastante generalizada, até mesmo entre os autores que a estigmatizam.

É curioso assinalar que as associaçōes inconscientes ou subconscientes que caracterizam a etimologia popular revelam, $\mathrm{Em}$ sua essência, uma inclinação natural do espírito humano em procurar uma explicação pronta e cômoda para as coisas desccnheridas, relacionando-as com outras que the sejam inteligiveis. Aliás, essa tendência pode ser observada na própria criança que, ao atingir o uso da razāo, começa logo a formular perguntas constantes sôbre tudo o que ignora ou tem dificuldade de compreender, estabelecendo comumente as mais engenhosas ou as mais descabidas analogias.

(1) 'La dénomination d'étymologie populaire... est très mauvaise, car elle donne à entendre que le sujet agit avec réflexion ce qui est faux". (DAUZAT: Hist. de la lang. franç., p. 234. Paris, 1934). "A etimologia popular prefere-se, hoje em dia, chamar atraçajo homonimica, uma vez que a designação antiga podia dar a entender a existência de uma consciência popular em inventar étimos - o que é absurdo." (SERAFIM NETO: Fontes do lat. vulg., p. 184. Rio. 1946). 
SAYCE, em magistral capítulo de sua obra Principes de Philologie Comparée, (1) assim se manifesta a respeito dêsse interessante assunto:

“L'esprit humain n'est pas satisfait tant qu'il n'a pas trouvé la raison d'être d'une chose, à moins qu'il ne croie la comprendre dès l'abord. Tant qu'il n'a pas trouvé cette explication, il se sent en présence de quelque chose de mysterieux et det surnaturel; cette ignorance lui cause tous les ennuis de la crainte et de l'incertitude. L'explication peut être très éloignée de la vérité, mais pourvu qu'il y en ait une, l'homme est satisfait. Pour expliquer, nous devons comparer; ce n'est qu'en plaçant un phénomène dans les limites du connu que nous le ferons sortir de la région de l'inexplicable".

O estudo dêste assunto, pôsto que irrelevante para o gramático, que só se preocupa com o aspecto normativo da língua, reveste-se de particular interêsse para o filólogo e para o lingüista, não só porque os habilita a resolver fàcilmente problemas que poderiam causar-lhes embaraços e dificuldades, como ainda porque os ajuda a conhecer mais um interessante processo psicológico de elaboração da linguagem popular. (2)

Por isso, o homem de ciência não pode encarar com desdém as formas oriundas da etimologia popular como se elas fôssem produtos meramente patológicos.

Daí a prudente advertência de HENRI FREl, quando escreveu:

"On aurait tort de considérer tous ces "accidents" comme des cas pathologiques; ils ne méritent pas tant de dédain.

Considérés dans leur ensemble, ils ont leur raison d'être, en ce qu'ils répondent à une tendence organique du système: le besoin de ramener l'inconnu au connu."

(La grammaire des fautes, P. 12)

Também o eminente Prof. PAIVA BOLEO, em magnífico trabalho divulgado na Revista de Portugal (3), põe em evidência a

(1) Trad. de JOVY, p. 265. París. 1884

(2) Cf. LEITE DE VASCONCELOS: Opúsculos, IV, p. 587 e I, p. 340

(3) Cf. vol. I, n. 3 (Série A), p. 129. 
importância do estudo da linguagem popular, ressaltando com muita sabedoria que "o lingüista ou o filólogo nāo se ri de certos vocábulos e expressōes populares; por muito estranhos e adulterados que the pareçam, têm quase sempre a sua razão de ser."

Vejamos agora alguns exemplos curiosos de criaçōes populares por atraçāo homonímica, uns observados por nós; outros extraidos em trabalhos sôbre o assunto:

1. Necromancia (gr. nekros, morte, e manteia, adivinhaçāo) é transformado pelo povo em negromancia, por influxo do elemento negro, donde a expressão "magia-negra".

2. Temos ouvido, por várias vêzes, o vocábulo antulho para designar a planta da familia das aroideas, vulgarmente chamada antúrio. É um caso típico de etimol. pop., em que antulho teria sido modelado por influência de entulho.

3. Esgatanhar aparece por esgadanhar, onde é evidente a interferência de gato.

4. Sacristão transformou-se em sancristão por influência de santo (são).

5. Pelegrino por peregrino ocorre não só no Brasil como também em Portugal, segundo o testemunho de Adolfo Coelho. (1) Teria havido influxo da palavra pele?

6. Preamar, composto de prea (lat. plena, cheia) + mar, quando esta palavra era feminina, alterou-se em praiamar, porque o povo, desconhecendo o elemento prea, relacionou-o com praia, influenciado ainda por mar.

7. Por influxo de ouro, vemos urina transformada em ourina.

8. Leite de Vasconcelos registra Santanás por Satanás, influência de santo, "que se vislumbra em santuário, mas talvez com um pouco de ironia, porque o diabo não é tão feio como o pintam". (2)

9. Larva alterou-se em lavra por influência de lavrar.

10. Adolfo Coelho lembra o vocábulo pantomima, que é às vêzes alterado para pantomina, por interferência de mina. No Brasil verifica-se o mesmo fenômeno.

(1) Quest. de ling. port., 1, p. 109.

(2) Opúse., I, p. 344 . 
11. Aeroplano passa para areoplano, onde se vê o influxo de ar.

12. Sobrancelha sofreu influência de sombra, donde a forma vulgar sombracelha.

13. Outro exemplo já bem conhecido, nâo só no Brasil como em Portugal e na Espanha (1), é vagamundo por vagabundo (lat. vagabundu, errante), por influência de mundo.

Camilo, que comumente se' abeberava na fonte popular, não se correu de empregá-lo bastas vêzes em suas obras admiráveis, bem como os cognatos vagamundear (2) e vagamundeação (3).

14. Cogote modificou-se em cangote, já registrado em alguns dicionários. Houve interferência de canga.

15. Altomóvel por automóvel é muito comum, porque o elemento alto é mais familiar à gente inculta do que o prefixo gr. auto.

16. Samambaia, planta da família das polipodiáceas, aparece freqüentemente alterada para sambambaia, por influxo de samba.

17. Lavadeira, segundo Leite de Vasconcelos, (4) é forma oriunda de lavandeira, donde lavandaria, por influência de lavar $(+d+$ eira).

18. Cobreiro em vez de cobrelo está de tal modo generalizado na linguagem brasileira que os dicionários mais modernos já lhe deram guarida. Houve influxo do sufixo eiro.

19. Abóboda por abóbada teria sofrido influência de abóbora. Também se pode admitir tivesse havido assimilação. (5)

20. Frontespício é modificação de frontispício por influxo de fronte.

21. Por influência de monstro a palavra mostrengo alterou-se em monstrengo.

22. Impingem, no Brasil, parece mais comum do que impigem (impetigo ou impetigem, erupção cutânea), por interferência de impingir.

(1) Vi. MENÉNDEZ PIDAL: Man. de gram. esp., p. 196, ed. 1941.

(2) Cf. Coisas esp., p. 10. Lisboa, 1862.

(3) Cf. Luta gig., p. 9, ed. 1865.

(4) Cf. Liç. de filol. port., p. 207. Lisboa, 1926.

(5) Vi. ISMAEL COUTINHO: Pontos de gram. hist., p. 153. Rio, 1954. 
23. Selvicula, que figura em alguns livros brasileiros, é alteraçāo de silvicula, influenciada por selva.

24. Lagarto modificou-se em largato por interferência de largar.

25. Marcela-galega, tão frequiente na bôca do povo, é alteração de macela-galega, por influência no n. p. Marcelo.

26. Pancadaria de mouro passou a pancadaria de môlho.

27. A frase corrente cuspido e escarrado é adulteração de esculpido e encarnado.

28. Trazer à colação alterou-se em trazer a coleção.

29. Falar francês como um basco espanhol transformou-se em falar francês como uma vaca espanhola.

30. Quarador é modificaçāo de coradouro, por influência de quarar.

31. Prescutar por perscrutar, porque o povo desconhece 0 elemento pers.

32. Estalar por estrelar (com relação a ovos) em virtude do barulho de frigir.

Verifica-se a etimologia popular entre pessoas semicultas quando o têrmo ativo, ou que exerce influência, é desconhecido das pessoas incultas.

Para exemplo, podemos mencionar as formas legisferar (influência do vocábulo sinónimo legislar) e estigmatismo em vez de astigmatismo, onde se percebe 0 influxo de estigma.

Essas adulterações popuiares são muito freqüentes em palavras e frases estrangeiras, como vamos apreciar:

1. Mortandela, forma já bem generalizada na linguagem brasileira, é modificação de mortadela, do ital. mortadella, por influência de mortandade.

2. Camapé resultou do francês canapé por influxo de cama.

3. Hortelä-pimenta representa o latim hortulana mentha, onde mentha sofreu influencia de pimenta.

4. Do adágio latino necessitas caret lege (a necessidade está acima da lei) o povo fêz a necessidade tem cara de herege. 
5. Ó tempora! ó mores! é modificado em - ó tempo dos amôres, e ainda - é tempo dos mouros!

6. Lei marcial, segundo João Ribeiro, resultou do inglês Marshall Law. Marshall "é o nome da pessoa a que está ligado êsse procedimento militar nos momentos de perigo. A Marshall Law passou de Albion para o continente, e foi logo transformado em lei marcial, ainda que Marte em nada influísse nessa derivação".

Marshall passou a marcial por ser êste vocábulo familiar ao povo.

7. Uma canção folclórica do ciclo de Natal termina pelo verso: Clória no céu se deu, que nada mais é do que a transformação de Cloria in excelsis Deo. (1)

8. Janua coeli alterou-se em já não há céu.

9. A expressão a par $\propto$ passo, de uso tão comum, é modificação de pari passu.

10. Te Deum foi traduzido em Tadeu.

11. João Ribeiro (2) registra ainda mais dois casos curiosos: missa de libra e meia, em que libra e meia é tradução de latim libera me; e clarabóia por claire-voie, onde a palavra "boia" não pôde derivar-se de "via" (clara via).

12. Os estivadores brasileiros deram o nome de camondongos aos grandes guindastes em que trabalhavam nas nossas docas.

Medeiros e Albuquerque foi o primeiro a explicar o fato, mostrando tratar-se de uma corruptela popular assim explicada:

"Os tais guindastes vieram dos Estados-Unidos $\epsilon$ os primeiros maquinistas que funcionaram nas docas foram norte-americanos contratados.

Ora, êsses operários falavam naturalmente inglês. Assim. quando queriam ordenar a descida do cabo, gritavam: -Come down!, isto é, desça!

O nosso povo, não entendendo a algaravia, fêz de come down "camondongo". Tradução pitoresca..." (3)

(1) Cf. GUSTAVO BARROSO: Ao som da viola, p. 145.

(2) Cf. Curiosidades verbais, p. 151. ed. s/d (1927).

(3) $V_{i}$. JOAQUIM RIBEIRO: Estética da língua portuguêsa, p. 155. Rio, s/d. 
E assim finalizamos aqui o nosso modesto trabalho.

Com êle queremos prestar a nossa sincera e comovida hoarnażem ì merríria do grande Mestre da filologia portuguêsa, $\therefore$ Juse Lcite de Vasconcelos, cujo centenário de nascimento, ocorrido no ano de 1958, se comemorou solenemente em Portugal e no Brasil, e cuja vida gloriosa constitui um exemplo dignificante de amor aos estudos e dedicação ao trabalho.

\section{FONTES DE ESTUDO}

J. LEITE DE VASCONCELOS: Opúsculos, vol. I, p. 344. Coimbra, 1928.

Id., ib., vol. IV, p. 587. Coimbra, 1929.

Id., Liçōes de filologia portuguèsa, p. 207. Lisboa, 1926.

Id., in Miscellanea di filologia, dedicata alla memoria dei professori Caix e Canelo, p. 263. Firenze, 1886.

I. J. NUNES: Compêndio de gramática histórica portuguêsa, vol. II, p. 115. Lisboa, 1907.

RIBEIRO DE VASCONCELOS: Gramática histórica da língua portuguêsa, p. 100, S/d (1901).

CAROLINA M:CHAELIS DE VASCONCELOS: Liçöes de filologia portuguêsa, p. 39, ed. Ca "Revista de Portugal". Lisboa, s/d.

JOÃO DA SILVA CORREIA, in "Revista Lusitana", n. XXX, p. 98. Lisboa, 1932.

ADOLFO COELHO: Questōes da lingua portuguêsa, vol. 1, p. 109. Pôrto. 1874.

MANUEL DE PAIVA BOLÉO. in "Revista de Portugal", (série A), vol, I, n.

3, P. 129.

JOÃO RIBEIRO: Estudos filológicos, p. 112. Rio, 1902.

JOÃO RIBEIRO: Curiosidades verbais, p. 151.

ISMAEL DE LIMAA COUTINHO: Pontos de gramática histórica, p. I - Rio, 1958.

MÁRIO BARRETO: Novos estudos da lingua portuguêsa, p. 311 , ed. 1921.

JOAQUIM RIEEIRO: Estética da lingua portuguêsa, p. 155. Rio, s/d.

SERAFIM DA SILVA NETO: Fontes do latim vulgar, p. 265. Rio, 1946.

Cônego BUEN!O DE SEQUEIRA: A ação da analogia no português, p. 34 . Belo Horizonte, 1950.

CUSTAVO BARROSO: Ao som da viols, p. 145. Rio, 1921.

A. H. SAYCE: Principes de philologie comparée, p. 265. Trad. de E. JOVY. Paris, 1884.

ALBERT DAUZAT: La langue française d'aujourd'hui, p. 44. París, 1912.

Id. La vie du langage. p. 130. Paris, 1918.

Id., La langue française, sa vie, son évolution, p. 51. Paris, 1926.

Id., Histoire de la langue française, p. 234. Paris, 1930.

M. MILLARDET: Linguistique et dialectologie romanes, p. 396. Paris, 1923.

A. DARMESTETER: La vie des mots, p. 132. Paris, 1927.

J. MAROUZEAU: La linguistique, p. 64. Paris, 1944.

J. VENDRYES: Le langage, p. 212. Paris, 1921. 